\title{
КОМИКС В КОММУНИКАТИВНОЙ ПРАКТИКЕ СОВРЕМЕННОГО ЧИТАТЕЛЯ
}

\author{
Виктория Широкоступ
}

\section{COMICS IN THE COMMUNICATIVE PRACTICE OF THE MODERN READER}

\begin{abstract}
Victoria Shirokostup
Резюме: В данной статье характеризуются основные понятия, связанные с изучением комикса как современного источника информации, рассматривается его специфика, виды. А также подводятся итоги практической части исследования.
\end{abstract}

Ключевые слова: комикс, креолизация, графика и параграфика, идеограмматизация, конвенциональность, иконическая система знаков.

Abstract: This article describes the main concepts associated with the study of comics as a modern source of information, examines its specifics, types. The results of the practical part of the research are also summarized.

Key words: comics, creolization, graphics and paragraphs, ideogrammatization, conventionality, iconic sign system.

DOI: $10.14712 / 9788076032088.18$

В современных условиях, когда ключевое внимание подростков направлено на социальные сети и Интернет в целом, тема феномена культурно-информационного характера очень важна. Комикс стал альтернативой книге, сначала в печатном виде, а позже и в электронном. Он набирает популярность, становится востребованной формой получения информации у подростков. Согласно исследованиям, чтение комиксов является упрощенной версией обычного чтения. Это связано с сочетанием в себе литературы и изобразительного искусства. Люди XXI-ого века предпочитают такой способ чтения из-за простоты восприятия информации. Этот факт уже исследуется в современной научной литературе. Человек не только читает и перерабатывает полученные сведения, проговаривая текст про себя или вслух, но и рассматривает картинки, а закрученный сюжет еще больше повышает его интерес к данному роду художественной литературе.

Однако данная тема еще изучена не полностью. В современном мире новые виды комиксов появляются чуть ли не каждый день в разных уголках планеты. Все они имеют разные критерии: возрастные, жанровые, стилевые и т.д. Комиксы становятся не просто детской книжкой с картинками, а полноценной конкурентоспособной современной литературой. И поэтому так важно продолжать исследовать ее влияние на современников. В этом и состоит актуальность данной работы.

Исходя из вышесказанного, в качестве объекта исследования мы выбрали комикс, а предметом нашей работы стала роль комикса в коммуникативной практике современного читателя.

Нас заинтересовало определение комикса Скотта МакКлауда, которое он использовал в 
своей книге «Суть комикса» (англ. Understanding comics) (МакКлауд, онлайн). Комиксист предложил краткое определение комикса как последовательного изображения, и более полное определение как смежного рисунка и другого изображения в смысловой последовательности. От этих определений мы и отталкивались в данной научной работе.

Рассмотрев тенденцию развития комиксов в разных странах и их влияние друг на друга, мы отметили, что комикс является одним из самых показательных примеров синтеза элитарного и массового, а также ярким представителем популярной культуры (см. работы Т. М. Беловой, Ф. Ван Ленте, А. И. Кунина, Ю. А. Магера и др.). Он соединяет черты таких видов искусства, как литература и изобразительное искусство, создающих единое повествование и визуальное действие. Среди основных особенностей комикса как источника информации мы выделили:

- полную креолизацию текста, т.е. сочетание вербальных компонентов, включающих в себя буквенный текст, и невербальных компонентов, включающих графику комикса (последовательность рисунков, каждый из которых обрамлен рамкой и образует кадр) и параграфику (дополнительную информацию, участвующую в создании экспрессивности и эмотивности текста) (Удод 2013);

- идеограмматизацию пространства комментариев и филактера (превращение текста в рисунок, а рисунок выступает в роли текста) и идеограмматизацию графем и знаков препинания (в результате чего появляются звукоподражания) (Столярова 2010);

- отнесенность комиксов к последовательному искусству, поскольку изображения следуют за изображением, складываясь в единую структуру;

- конвенциональные знаки (искусственно созданные знаки, которые люди "договорились" приписывать определенное значение);

- иконическую систему знаков (символическую).

Комиксы за свою короткую историю бытования уже успели выработать собственный язык визуальных символов. Использование глубокого кинематографического пространства, смены ракурса, масштаба или типа пространства часто играет роль мощного смыслового акцента (Куликова 2019). Таким образом, на основании всего вышесказанного мы отметили основные различия между визуальным языком иллюстрированной книги и комиксом:

1) разные подходы к зрительной трактовке времени и происходящих в нем событий:

а) комикс дробит время на множество кадров, каждый из которых заключает в себе все необходимое для полноценного восприятия, произошедшего в данный отрезок времени;

b) иллюстрированное издание содержит в себе текст, который идет сквозь книгу непрерывным потоком, а приостанавливающие это движение иллюстрации нередко сами отображают не столько конкретное мгновение, сколько обобщение некоего более крупного временного отрезка;

2) из первого отличия вытекает разница в компоновке текста и изображения:

а) в иллюстрированной книге текст - это единый и неразрывный поток, который проходит сквозь книгу по установленным художником правилам (размеры, пропорции и расположение текстовых блоков, кегль и гарнитура шрифта, и т. п.);

b) в комиксе текст так же, как и время, нарезается на «ломтики», распределяемые по отдельным кадрам, так что вновь прочесть их как целостный нарратив (повествование, рассказ), читатель способен только воспринимая их вместе с изображением, причем основную смысловую связующую роль здесь играет именно последнее.

Указанные свойства комикса позволяют выделить его в качестве особого жанра массовой культуры. Несмотря на гетерогенность его составляющих, он характеризуется высокой 
степенью их согласованности и целенаправленности в представлении информации. В современном мире востребованность комиксов растет, потому что они облегчают восприятие информации и увеличивают скорость ее усвоения. Изучение развивающегося языка графической прозы позволяет во многом понять путь дальнейшего развития средств массовой информации, раскрывает широкие перспективы во многих областях напрямую, либо косвенно связанных с языкознанием.

Нами была выдвинута гипотеза исследования о том, что комикс в современном мире выступает в роли одного из основных источников информации наряду с художественной классической / современной мировой литературой и изобразительным искусством. С целью определения специфики комикса как источника информации в современном мире, нами была составлена анкета. Приведем её основные вопросы и задания:

1. Продолжите определение. Комикс - это

2. Читаете ли Вы комиксы? Почему?

3. Какие из представленных ниже разновидностей комиксов Вам знакомы? Обведите нужную букву выбранного ответа.
А) Азиатские комиксы,
Б) американские комиксы,
В) европейские комиксы,
Г) российские комиксы (отечественные).

Назовите прочитанные Вами комиксы, если таковые имеются.

4. Считаете ли Вы комиксы популярными сегодня? Почему?

очень популярны

достаточно популярны

почти не популярны

совсем не популярны

5. Сравните комикс с художественной литературой и живописью. Определите их сходства и различия как источников информации.

Для того чтобы обосновать выдвинутую научную гипотезу и доказать теоретические выводы, к которым мы пришли на первом этапе своего исследования, мы разработали констатирующий срез с целью подтвердить или, напротив, опровергнуть собственные предположения в изучаемой области знаний. Респондентами констатирующего эксперимента стали учащиеся 9-11 классов МБНОУ «Лицей № 11» г. Новокузнецк. 50 человек приняли участие В данном анкетировании. В качестве экспериментальной группы были выбраны именно учащиеся старших классов, потому что мы посчитали данную возрастную категорию лиц наиболее осведомленной и заинтересованной в таком достаточно новом явлении искусства как комикс.

Отвечая на вопрос о том, что такое комикс, 93\% опрашиваемых определили термин «комикс» как последовательность рисунков с текстом, которые образуют сюжетное повествование. 7\% респондентов уточнили, что комикс - это история с небольшим текстом юмористического или приключенческого характера, изображенная в определенном стиле рисовки. Данный опрос показал, что такое явление как комикс, хорошо известно участникам опроса.

На вопрос о чтении комиксов 81\% опрошенных ответили, что не читают в данный момент комиксы; из них 52\% не могут читать комиксы (но хотели бы) из-за нехватки времени в силу каких-либо обстоятельств или из-за дефицита указанного жанра самих комиксов в стране; некачественный перевод зарубежных комиксов также попал в эту категорию. Остальные $48 \%$ 
отметили отсутствие интереса к чтению комиксов или объяснили свое нежелание обращаться к ним в силу того, что, по их мнению, такой формат им не удобен. По данным статистической обработки мы видим, что только $19 \%$ опрошенных учеников сейчас охотно читают комиксы.

Третий вопрос в анкете должен был показать осведомленность респондентов в разнообразии комиксов (азиатских, американских, европейских или российских), также опрашиваемые должны были привести примеры прочитанных ими комиксов. В качестве прочитанных комиксов были приведены: американские (The Walking deads, Fables, Star wars, Wolverine, Spider man, X-men, Batman, Teenage Mutant Ninja, Cars, Scooby-Doo, Madagascar, Deadpool, Iron Man, The Winter Soldier, Siege), азиатские (Оуasumi Punpun, Singeki no Kyojin, Berserk, Neon Genesis Evangelion, The Promised Neverland, Dorohedoro, Psycho-Pass, Jojo no kimyo na boken, Houseki no Kuni, Mo Dao Zu Shi, Naruto), европейские (Totally Spies, Blacksad), российские (Мурзилка, Приключение Шарика, Анна Каренина by Leo Tolstoy). Из данных опроса видно, что респонденты отдают предпочтение комиксам про супергероев, людей или хуманизированных (наделенных человеческими качествами или обликом) персонажей со сверхъестественным способностями. Большинство из перечисленных комиксов изображены в жанре «приключение» или «боевик», во многих из них представлены иные, параллельные и сверхъестественные миры.

Четвертый вопрос заключался в определении уровня популярности такого современного самостоятельного вида искусства как комикс. $80 \%$ опрошенных указали, что комикс «достаточно популярен» и "очень популярен» на сегодняшний день. Учащиеся указали такие причины как, во-первых, жанровая составляющая (супергеройство, фэнтези, приключение, боевик, магия и т.д.) - данные жанры, по их мнению, сегодня очень популярны, из чего вытекает второй фактор: экранизация комиксов, что еще больше поднимает уровень популярности данного жанра, кстати, по этому поводу есть мнение абсолютно противоположное. 4\% респондентов заявили, что именно из-за экранизации сюжета сами комиксы теряют свою популярность. В-третьих, по мнению опрошенных, комикс является популярным жанром чтения из-за простоты получения информации, то есть комиксы читаются легче, чем, например, художественная литература. А $19 \%$ людей, проголосовавших от данной категории, считают, что комиксы пользуются спросом из-за погони читателей за модой, за зарубежными новшествами, где комикс уже стал частью культуры населения.

Пятый вопрос был направлен на выявления сходств и различий между комиксом и живописью, комиксом и художественной литературой. По итогу анализа сходств между комиксом и художественной литературой выяснилось, что 73\% респондентов отметили наличие какого-либо события, сюжетных линий, действующих лиц и диалогов между ними, 54\% указали такие основные черты, как способ передачи информации или наличие текста. 42\% отметили наличие определенной структуры (завязки, кульминации, развязки), жанрового разнообразия, погруженность в атмосферу и эмоциональную наполненность текстов.

На основе результатов анкетирования мы сделали следующие выводы: все опрошенные школьники имеют представление о том, что такое комикс, однако их мнения расходятся в личном отношении к комиксам и в определении уровня популярности комиксов на сегодняшний день. Но при этом стоит отметить, что учащиеся в подавляющем большинстве точно определили сходства и различия между комиксом и художественной литературой и между комиксом и живописью. Иными словами, парадокс данного исследования заключается в том, что респонденты знают определение комикса, его виды, точно определяют специфику комикса как источника информации по сравнению с литературой и живописью, но сами комиксы читают мало или вообще не читают.

Современное поколение имеет полное представление о специфике комикса как средства получении информации и об особенностях реализации данного процесса. 
Определение сходств и различий комикса со своими прародителями литературой и живописью подтвердило, что комикс - это реальность современного общества, а возможно и его будущее. Главный аргумент - доступность изложения материала. Комиксы могут быть представлены в любом литературном жанре и в любом стиле изобразительного искусства. В них адаптируют даже произведения классиков литературы. Сегодня некоторые исследователи рассматривают комиксы как отдельный тип медиа и отмечают, что вхождение комиксов чем-то схоже с вхождением Интернета, когда возникает совершенно новая коммуникативная среда, которая полностью отражает желания потребителя. Это обязательная черта массовой культуры и литературы, но здесь она заиграла сильнее, поскольку добавился визуальный элемент, работающий равноправно с вербальным.

Отметим, что наша гипотеза о том, что комикс в современном мире выступает в роли одного из основных источников информации наряду с художественной классической и современной мировой литературой и изобразительным искусством была доказана полностью. На экспериментальном этапе исследования мы получили данные об исходном уровне знаний и умений школьников в области изучаемой тематики. Полученные результаты и понимание, что наше исследование не является всеохватывающим, привели нас к выводу о необходимости сформулировать возможные направления перспективного развития нашей работы в дальнейшем. Приведем приоритетные, на наш взгляд, варианты развития выбранной нами для изучения темы:

1) более детальное изучение специфики комикса как источника получения информации с учетом более расширенного круга аудитории респондентов по гендерным и возрастным особенностям;

2) определение возможности использования комиксов в педагогической сфере.

\section{Использованная литература/ References}

\section{Печатные источники:}

БЕЛОВА, Т. М. (2015): Комиксы как средство выражения этнокультурных стереотипов. In Вестник Кемеровского государственного университета. Кемеровский государственный университет, 2015. 220 с. ISSN 2078-8975.

ВАН ЛЕНТЕ Ф.; Данлеви Р. (2019): История комиксов: научно-популярное издание. Москва : Манн, Иванов и Фербер. 224 с. ISBN 978-5-00146-345-0.

ЗАХАРОВА, М.В. (2016): Комикс как способ передачи смыслового контента в историко-культурном аспекте. In Культурология и искусствоведение: материалы II международной научной конференции. Казань : Бук. С. 1-3. ISBN 978-5-906873-06-4.

КОБЕЛЬСКАЯ, В. Э. (2019): Комиксы. Их влияние на общество. In Старт в науке. С. 222-227.

КУЛИКОВА, Н. Э. (2019): Комикс как вид визуального искусства. In ОГАРЁВ-ONLINE. Национальный исследовательский Мордовский государственный университет им. Н.П. Огарёва. еISSN 2311-2468.

КУНИН, А. И. (2013): Комикс в России. In Библиография. Научный журнал по библиографоведению, книговедению и библиотековедению. Издание: Библиография, 2013. С. 45-55.

СтоляРОВА, Л. Г. (2010): Анализ структурных элементов комикса. In Известия Тульского государственного университета. Гуманитарные науки. С. 383-389. ISSN 2071-6141.

УдОД, Д. А. (2013): Креолизованный текст как особый вид паралингвистически активного текста. In Современная филология: материалы II международной заочной научной конференции. С. 97-99. ISBN 9785-87308-039-7. 


\section{Онлайн-источники:}

Магера, Ю. А. (онлайн): История появления первых японских комиксов на русском языке. In Японские исследования. С. 6-23. elSSN 2500-2872. [дата обращения: 1.04.2020].

МакКлауд С. (онлайн): Суть комикса. Режим доступа: https://acomics.ru/ understanding-comics/3. [дата обращения: 25.03.2020].

Черняк, В. Д. (онлайн): Массовая литература в понятиях и терминах : учебный словарь-справочник.

Москва : ФЛИНТА, 2015. 192 с. - Режим доступа: -https://e.lanbook.com/reader/book/70425/

\section{Профиль автора:}

Виктория Широкоступ, студентка 3 курса факультета филологии Новокузнецкого института (филиала) ФГБОУ ВО «Кемеровский государственный университет»

Научный руководитель: Афранасенко Оксана Борисовна, кандидат педагогических наук, дочент

Научные интересы: коммуникативная культура педагога-филолога, речевая практика современников, теория и методика обучения русскому языку и литературе, школьное и вузовское филологическое образование.

e-mail: oks-afanasenko@mail.ru

Место работы: Новокузнецкий институт (филиал) ФГБОУ ВО «Кемеровский государственный университет», факультет филологии, кафедра русского языка и литературы, МБНОУ "Лицей №11"; г. Новокузнецк, ул. Тольятти, д. 28, кв. 15, индекс: 654080, Россия.

\section{Author's profile:}

Victoria Shirokostup, 3rd year student of the faculty of Philology of Novokuznetsk Institute (branch) Kemerovo state University

Scientific supervisor: Afanasenko Oksana Borisovna, candidate of pedagogical Sciences, associate Professor Research interests: communicative culture of a philologist-teacher, speech practice of contemporaries, theory and methodology of teaching Russian language and literature, school and University philological education. e-mail: oks-afanasenko@mail.ru

Place of work: Novokuznetsk Institute (branch) Kemerovo state University, faculty of Philology, Department of Russian language and literature, Lyceum no. 11, Novokuznetsk, Tolyatti str., 28, sq. 15, index: 654080, Russia. 